\title{
PRESUPUESTOS SOCIOHISTÓRICOS Y LITERARIOS DE LA LITERATURA HEROICA
}

\author{
Luis A. Acosta
}

El objetivo de este estudio consiste en la presentación y explicación de la evolución de la literatura heroica germánico-alemana y de las diferencias existentes entre sus dos formas de manifestación, canto heroico y epopeya heroica ( a. Heldenlied y Heldenepos) teniendo en consideración los presupuestos y condicionamientos histórico-sociales y literarios de los momentos en que ambos géneros hacen su aparición.

La investigación sobre la literatura heroica se remite al siglo XVI. Sin embargo, durante mucho tiempo su objeto no fue considerado autónomo, sino solamente como una manifestación de la historia o, a lo sumo, de la historia de la cultura germánicas o alemanas.

Durante el romanticismo comenzó a tomarse gran interés por lo primitivo y originario de la historia de los pueblos y, dentro de ello, por las manifestaciones literarias más ancestrales. Es en la época romántica cuando, por primera vez, la literatura heroica se investiga como una realidad autónoma e independiente. Jakob Grimm dio un impulso inicial muy importante a una investigación científica, en un sentido moderno de la palabra, con su obra de 1829 Die deutsche Heldensage. En este trabajo recopiló 230 documentos, estudios y testimonios histórico-literarios sobre el tema. Su intención fue indagar fundamentalmente en el origen, naturaleza y desarrollo de la saga heroica, sin tomar partido por ninguna de las dos teorías de la época sobre el origen de la saga a partir del mito o del cuento respectivamente ${ }^{1}$.

La investigación posterior continuó básicamente el camino abierto por Grimm. Sin embargo se introdujeron nuevos aspectos, nuevos puntos de vista y, en algunos casos, hasta nuevas orientaciones. Así, las grandes aportaciones, varias de ellas consideradas clásicas, de especialmente la primera mitad del siglo XX de científicos como Jiriczek, Deutsche Heldensage, 1898; Heusler, Lied und Epos in germanischer Sagendichtung, 1905; Die altgermanische Dichtung, 1923; L. Wolf, Die Helden der Völkerwanderungszeit, 1928; H. Schneider, Germanische Heldensagen, 1928-34; H. Schneider / W. Mohr, "Heldendichtung"; Th. Frings, Europäische Heldendichtung, 1938; H. Kuhn "Germanische Kultur und Dichtung", 1938; E. Mudrak, "Die deutsche Heldensage" 1939; G. Baesecke, Vor- und

${ }^{1}$ Cfr. W. Betz, "Die deutsche Heldensage", W. Stammler (Hrsg.), Aufriß der deutschen Philologie 3, (1956), pág. 1886. 
Frühgeschichte des deutschen Schrifttums, 1940-1953; C.M. Bowra, Heroic poetry, 1952; J. de Vries, Betrachtungen zum Märchen, insbesondere in seinem Verhältnis zum Mythos und zur Heldensage, 1954; Heldenlied und Heldensage, 1961; F.R. Schröder, "Mythos und Heldensage", 1955; F. Genzmer, "Vorgeschichtliche und frühgeschichtliche Zeit", 1962; sin pasar por alto otros, como Panzer, Schröder, Wais, de Boor, Höfler, Kuhn, Betz etc.

Esta investigación amplia y continuada ha encontrado muchas y casi siempre dificultades insuperables, de manera especial en lo referido al surgimiento y desarrollo del canto heroico ${ }^{2}$ (a. Heldenlied), debido en principio a la escasez de materiales trasmitidos, pero sobre todo porque la mayor parte de los trabajos se han elaborado desde planteamientos positivistas e inmanentistas. Los resultados han sido en la mayor parte de los casos explicaciones intratextuales, interpretaciones de los textos teniendo en cuenta la tradición, en que raras veces se han incluído consideraciones sobre elementos contextuales de naturaleza literaria, y nunca social, histórico-cultural, ideológica, política etc. La consecuencia de todo ello ha sido no pocas veces la caída en un círculo vicioso que no ha podido ser superado.

El interés de este trabajo se orienta desde una concepción específica de la literatura. La literatura se entiende aquí como un mundo amplio y complejo, un entramado amplio, dentro del que tienen lugar múltiples relaciones de índole diferente, que podría entenderse, tal y como hoy día se denomina en círculos críticos amplios, sistema literario. Los individuos que lo componen se constituyen como realidades co-textuales y contextuales que han evolucionado a lo largo de la historia literaria. Esto supone entender la obra, de un lado, como una realidad que tiene su existencia junto a individuos de igual o similar naturaleza literaria; por otro lado, como una realidad que tiene lugar dentro de múltiples condicionamientos.

En el marco de este sistema, el hecho literario se configura según los esquemas de un género específico, según una gramática de género que, por lo general, es susceptible de transformación. Este hecho literario de naturaleza codificada se manifiesta en un momento dado como un eslabón dentro del proceso general de evolución, en el que, o bien ha confirmado el esquema tradicional de género o bien se han infringido sus normas. La confirmación o infracción de las mismas es una consecuencia del ejercicio de la función estética de la obra dentro de procesos dinámicos, multifactoriales e interdependientes, que se desarrollan a lo largo de periodos extensos de tiempo. Cuando una forma específica de codificación genérica no tiene más que decir, es debido a que se ha producido un desgaste y no responde ya a las expectativas que se han creado sobre su función. Lo que ocurre entonces es que dentro del proceso permanente de constitución y cambio de horizonte surje una nueva configuración. La fijación de la función estética está directamente relacionada con la sociedad o grupo social en que se da el hecho literario y el propio hecho literario presupone una sociedad o grupo social que ejerce en ella su influencia. La función estética de la obra de literatura presupune, así mismo, una conciencia estética que canaliza la tensión que se

\footnotetext{
2 Término preferido al de 'canto épico'
} 
produce entre entre la estructura de la norma literaria entendida como arquetipo y la nueva configuración estructural.

Desde estos presupuestos básicos, el objeto de estudio se aborda mediante un análisis de la época literaria en que se ha cultivado el género, se trate de la época en que ha surgido, de aquella en la que se ha desarrollado, de aquella en que se ha transformado o de aquella en la que ha dejado de existir. Este análisis incluye la comprensión del contexto histórico, dentro del que han tenido lugar todos aquellos hechos, hayan sido de la índole que hayan sido, que de alguna manera han ejercido su influencia en el proceso de surgimiento y desarrollo del género, de los que hay que destacar fundamentalmente los acontecimientos históricos y también políticos; la comprensión de un contexto social, en el que se ha establecido una organización específica de la convivencia ciudadana y la comprensión del contexto cultural que implica también las formas de apropiación de la literatura.

No obstante, un análisis de esta naturaleza de los distintos contextos mencionados, en que se ha cultivado el género, y de las repercusiones que suponen para el mismo, no implica una relación de causa-efecto. Esto se explica desde la idea de que en todo proceso históricoevolutivo siempre emergen fuerzas y energías que actúan de manera libre y que ejercen su influencia en la actividad cultural y literaria, sobre las que no siempre se encuentra una explicación satisfactoria.

Dentro de la comprensión de esta complejidad de fuerzas encontradas y coincidentes, la comprensión del contexto literario adquiere una relevancia fundamental. En él se dan dos vertientes bien diferenciadas: una vertiente actual en la que convergen las simultaneidades literarias de un momento de la evolución, y una vertiente del pasado constituída por la tradición del género heroico. Pues ocurre, por un lado, que una época de la historia de la literatura desarrolla formas de configuración literarias específicas que se comvierten en dominantes; por otro, que la fuerza de la tradición es una realidad que está omnipresente ejerciendo su influencia sobre las fuerzas dominantes del presente. Ambas vertientes determinan y explican la razón de ser y naturaleza del objeto de comprensión.

Aunque el objetivo aquí propuesto no va tan lejos, es un hecho que la historia de la literatura heroica germánico-alemana se extiende a lo largo de aproximadamente un milenio. Son los siglos comprendidos entre el V de nuestra era, hasta, al menos, el XVI. Se trata, por tanto, de un periodo de historia literaria muy largo y las obras producidas en sus primeros siglos apenas han sido transmitidas. Es el periodo precisamente del momento de constitución y primer desarrollo, cuya reconstrucción resulta una operación muy laboriosa y prácticamente imposible de realizar en su totalidad. Por otra parte, además, durante los primeros siglos de este milenio tiene lugar una cesura histórica, cultural y lingüística de relevancia capital, que determina profundamente la evolución del género heroico.

Los materiales básicos de que se dispone son los siguientes: 1. El Hildebrandslied de principios del siglo IX; 2. El Heldenepos de título Waltharius de finales del X o principios del XI; 3. Los cantos heroicos - en antiguo nórdico (islandés)- recogidos en los Edda. 4. La compilación-traducción en antiguo noruego del bajo alemán de hacia 1260 Thidrekssaga; 5. 
La "Vorzeitsaga" islandesa de finales del XIII Hervararsaga (nor. Hervarar saga ok Heidreks Konungs = a. Die Geschichte von Hervör und Königs Heidrek); 6. Toda la literatura heroica conservada desde el Nibelungenlied hasta que el género deja de existir.

Estos hechos obligan a que la amplitud de esta investigación se restrinja, en primer lugar, a aquella parte de la literatura germánica, que con el paso del tiempo va a ser alemana y que encuentra su reflejo en el Hildebrandslied; en el periodo propiamente alemán, la restricción será al Nibelungenlied. Ambas obras serán el punto de referencia sobre el que se fundamenta todo este estudio; el Hildebrandslied como muestra ejemplar del primer periodo o periodo del canto heroico, y el Nibelungenlied como ejemplo paradigmático del segundo o periodo de la epopeya heroica o cantar de gesta.

La forma de manifestación inicial de la literatura heroica son las sagas. Se trata de una literatura, cuyo surgimiento coincide con un momento importante de la historia de un pueblo; en él se producen hechos que tienen una relevancia muy especial, y que van acompañados siempre de acontecimientos guerreros. Según Chadwick, toda época heroica es un momento de grandes convulsiones y se caracteriza por el dominio de una aristocracia guerrera $^{3}$. Este hecho constituye el punto de partida para la constitución de los materiales sobre los que se desarrolla una historia que luego va a ser contada en forma de saga.

La saga heroica, por su parte, como forma específica de esta literatura, se entiende como el elemento material de formas literarias que cuentan hechos que han sido protagonizados por héroes. Una vez que se ha convertido en literatura, es en la forma de uno de los dos códigos de conformación literaria heroica: canto heroico (a. Heldenlied) o epopeya heorica (a. Heldenepos). La saga heroica rinde culto a la personalidad, encarna una visión idealista y trágica de la existencia y una conciencia "nacional" o de grupo. Los protagonistas de las sagas heroicas son seres extraordinarios que pueden, incluso, provenir de la divinidad, que disponen de una fuerza física excepcional. Es una personificación de los ideales de un pueblo del que es miembro y en él se reflejan las cualidades más preciadas del mismo. Es un prototipo a imitar y a alabar y, por tanto, también digno de ser "cantado".

Una de las cuestiones más importantes en el estudio de las sagas es la relativa a su origen. Las opiniones más generalizadas lo fijan bien en el mito ${ }^{4}$ bien en el cuento ${ }^{5}$. Por lo que se refiere a la primera, la discusión se ha centrado en el punto sobre si el origen se localiza en la dirección que va desde el mito hasta elementos de la historia, o más bien en la dirección opuesta, es decir, desde la histoira, pero incluyendo elementos míticos. Sea como fuere, parece que en la saga pueden identificarse elementos procedentes de tres fuentes distintas: del mito, del cuento y de la historia. En cualquier caso, la fuente principal de las sagas germánico-alemanas es la historia, sin que ello excluya en modo alguno la presencia de elementos míticos.

3 Cfr. H.M. Chadwick, The Heroic Age (Cambridge 1912). Citado según G. Zink, "Heldensage", Kurzer Grundriß der germanischen Philologie 2 (1971), págs. 1-2.

${ }^{4}$ Así Andreas Heusler, Franz Rolf Schröder, Jan de Vries, Otto Höfler y Karl Hauck.

${ }^{5}$ P. Panzer ha sido el defensor más destacado de esta teoría. 
Independientemente de su origen, el hecho es que la saga en un momento determinado cobra entidad literaria. Es un desarrollo que, según afirma Betz, pasa por tres momentos, de los que el primero ha sido dominado por las fuerzas del destino, dios o la religión; el segundo por el honor, el estado o la política; y el tercero por el amor, el hombre o el sentimiento ${ }^{6}$. Sowinski, bajando más al detalle, identifica cinco momentos distintos en el proceso de evolución de la misma: en el primero la saga sería una narración de acontecimientos histórico-políticos, familiares o míticos; en el segundo un informe baladesco con inclusiones formales de tipo dialógico; en el tercero, un canto heroico de extensión reducida; en el cuarto, un cantar heroico genuino; y en el momento final, una forma de balada o canto popular?

Es en el tercer momento de esta evolución cuando tienen lugar los acontecimientos históricos que constituyen los temas de la mayor parte del repertorio de sagas trasmitidas. Coincide además con el de máximo desarrollo del canto heroico (a. Heldenlied). Pero a partir de entonces ya no se crean más sagas, a pesar de que se sigue creando literatura heroica, lo que ha de explicarse desde la consideración de que la época heroica ha terminado ya con el final de las grandes migraciones.

Desde el momento en que surge una saga pueden sobrevenirle dos destinos diferentes: puede courrir que o bien se desarrolle en sucesivas versiones hasta su desaparición antes de agotarse la época de la literatura heroica, o bien continúe su existencia hasta el final de la historia de esta literatura. Puede ocurrir, además, que por múltiples razones los contenidos de sagas diferentes entren en contacto entre sí, mezclen sus contenidos, estructuren la acción dentro de circunstancias diferentes y surjan nuevas versiones que, en algunos casos, no encuentran identificación plena con la presumible forma original. El resultado de todo ello son los distintos ciclos de sagas que se extienden en forma literaria hasta la época moderna y que pueden reducirse prácticamente a una decena: Sage von der Hunnenschlachtlied, Ermanarich-Sage, Dietrichsage, Wielandsage, Nibelungensage, Walthersage, Gudrunsage, Sage von Wolfdietrich und Ornit.

Si examinamos, aunque sea sólo de una manera superficial, el único canto heroico (a. Heldenlied) conservado en lengua alemana, nos encontramos con hechos que llaman la atención. Junto a nombres de personajes históricos de relevancia como Dietrich (Teodorico) u Odowakar (Odoacro), aparecen otros de total irrelevancia histórica como Hildebrand o Hadubrand. Todos ellos son personajes que han existido durante la época de las grandes migraciones de los pueblos germánicos (a. Völkerwanderungszeit). Se observa igualmente que se trata de personajes que pertenecen a un estamento privilegiado y que son portadores de una visión de la existencia y las relaciones humanas propia de una época heroica. Los acontecimientos son hechos históricos muy importantes que han llevado a enfrentamientos y luchas cuya solución ha sido siempre una solución trágica. Las relaciones entre los

\footnotetext{
${ }^{6}$ Cfr. W. Betz, "Die deutsche Heldensage", pág. 1961.

7 Cfr. B. Sowinski, "Das Heldenlied", Formen der Literatur. Edic. de O. Knörrich, Kröner (Stuttgart 1981), p. 158
} 
personajes parecen entenderse desde los principios del honor, la fidelidad, la valentía y la comprensión de la muerte como única salida.

Estos contenidos se configuran literariamente en una estructura narrativa dialogada de no mucha extensión, cuyos elementos formales se extraen de una tradición literaria ya confirmada, que consiste en recursos aliterantes y figuras retóricas elementales y una versificación irregular. El motivo literario tradicional en literaturas indoeuropeas del padre y del hijo otorga apoyatura al contenido.

Algo similar se observa si se analiza el repertorio de los cantos heroicos recogidos en los Edda.

Con todo, en este canto heroico se observan todavía otros aspectos que no encuentran explicación satisfactoria si se intenta hacerlo desde esta perspectiva de observación inmanentista. El análisis de los contextos histórico, social, político y literario pueden despejar insuficiencias.

Los materiales sobre los que están construídos la mayor parte de los cantos heroicos proceden son de la época de las grandes migraciones. Es una época de la historia en que se han visto implicados no sólo pueblos pertenecientes al mundo germánico de entonces, sino también otros pueblos vecinos como los hunos, pero de una manera muy especial el mundo romano de la época imperial final. En ella - son los siglos del I al VI ${ }^{8}$ - tiene lugar un proceso de transformación política y social, cuya resultado será una síntesis de elementos de procedencia fundamentalmente germánica y romana ${ }^{9}$.

El proceso migratorio no es una acción de un grupo aislado, sino un conjunto de acciones colectivas de grupos heterogéneos dirigidos por reyes o caudillos (a. Heerkönige) procedentes de grupos de organización social (a. Sippen) famosos.

En la época de las grandes migraciones se observan tres fenómenos que se hace necesario destacar: la desintegración del imperio romano, el proceso de emigración germánica y el hecho de que los protagonistas sean sobre todo germanos orientales. Dentro de ellos destacan, a su vez, tres acontecimientos o series de acontecimientos: la irrupción de los hunos en el año 375, la penetración de pueblos germánicos, como visigodos, vándalos y burgundios en el imperio romano y el establecimiento de relaciones con Roma; y, como se ha mencionado ya, el momento final del imperio romano de occidente, momento en el que las figuras de Dietrich (Teodorico) u Odowakar (Odoacro) cobran una relevancia histórica especial.

Si se intenta una explicación de estos hechos histórico, puede llegarse a dos conclusiones: que el movimiento migratorio es de tal envergadura que puede ser considerado único en la historia. Durante el mismo la vida se desarrolla dentro de un ambiente de

\footnotetext{
${ }^{8}$ La irrupción de los hunos tiene lugar en el año 375; en el 568 los langobardos conquistan el norte de Italia

${ }^{9}$ Aunque de menor importancia para el momento, conviene, no obstante, no olvidar la aportación de los celtas. Será de capital importancia en la configuración del sistema socio-político que surgirá más tarde y que se extenderá a lo largo de siglos.
} 
permanente convulsión a consecuencia de situaciones contínuas de tensión, guerras interminables y la experiencia diaria de la muerte. De otro lado, el contacto con el mundo antiguo latino y la asimilación parcial o el rechazo de su concepción de la existencia, desarrollo social, político, religioso y cultural, lleva a la situación de tener que conjugar la victoria de las armas con el enfrentamiento y sometimiento a un desarrollo cultural mucho más evolucionado. La convulsión es todavía mayor cuando estos pueblos se sienten portadores de una herencia sociocultural propia que pretende sobrevivir. La síntesis final será el resultado de un proceso muy doloroso.

Durante la época de las grandes migraciones (a. Völkerwanderungszeit) dentro las distintas sociedadades germánicas surgen como forma de organización comunidades tribales (a. Stammesverbände). Con anterioridad la unidad social elemental consistió en un grupo familiar relativamente pequeño organizado según una estructura patriarcal. De la integración de otros familiares, allegados o amigos surgió la Sippe, y de la unión de varias el Stamm. Según el informe de Tácito en su Germania pueden decucirse dos peculiaridades fundamentales de la Sippe. De un lado, que se trata de una agrupación de hombres libres, de otro, además, que estos hombres libres tienen relación de parentesco. La época de las grandes migraciones crea, por razones obvias, una situación de dependencia, dado que la Sippe garantiza apoyo, protección e, incluso, promoción. Para un funcionamiento efectivo de sus miembros se espera como condición indispensable la lealtad, de forma que mediante el juramento de fidelidad se obliga a los miembros no sólo a prestarse ayuda mútua, sino también a relizar actos de veganza, dado el caso de que se haya cometido una ofensa a un miembro de la Sippe, para, de esta manera, poder salvaguardar el honor ${ }^{10}$.

En la estructura jurídico-política del estado emergente sólo tienen cabida los miembros del Stamm y sólo disfrutan de plenos derechos quienes son idoneos para la lucha. Ahora bien, dentro de estos ciudadanos de plenos derechos existen diferencias que vienen dadas por la Sippe de la que proceden. De ello surge una estructura social configurada en tres grupos: el primero constituído por los nobles (a. Vollfreie; lat. nobiles, principes, proceres); el segundo, por hombres libres (a. Minderfreie; lat. liberi, ingenui, plebs); y el tercero por hombres no libres (a. Unfreie; lat. indoles). Al primero pertenecen los reyes, duques y campesinos de grandes propiedades; al segundo, quienes no tienen esa categoría, pero que disfrutan de ciertos privilegios; y al tercero los ciudadanos de derechos disminuidos ${ }^{11}$.

La soberanía política radica en la totalidad de los hombres libres útiles para la guerra, quienes toman decisiones en el consejo (a. Thing; lat. concilium) y eligen rey, originariamente a miembros de prestigio procedentes de buena estirpe. Como caudillos (a. Heerkönige) desempeñan durante la época de las grandes migraciones la función de crear una organización política, un pequeño nuevo estado en el territorio extranjero ocupado.

10 Cfr. V. Kellermann: Germanische Altertumskunde. Einführung in das Studium einer Kulturgeschichte der Vor- und Frühzeit. Schmidt (Berlín 1966), págs. 27-28.

${ }^{11}$ Cfr. ibid., págs. 30-31. 
Durante esa época esta estructura socio-política comienza paulatinamente a experimentar una profunda transformación, que se manifiesta de manera más ostensible en el fenómeno que constituye el surgimiento de la nobleza. La importancia de este hecho puede calcularse por las repercusiones que va a tener a lo largo de toda la edad media. Valga aquí con hacer referencia al significado de la palabra Adel (e. nobleza) que, de procedencia etimológica del a.a.a. adal, significa, según Gebhardt, además de propiedad, también familia, estirpe e incluso soberanía. Esta nobleza incipiente de índole campesina es, en definitiva, una élite social, una minoría de auténticos hombres libres, que protagonizará la organización política del estado durante toda la edad media. Su carácter aristocrático encontrará la forma de dominio en la organización monárquica.

Para la defensa de los intereses del grupo a nivel de Sippe o Stamm, se crea una organización que se conoce como Gefolgschaft, materializada en el Gefolge (e. séquito; lat. comitatus). En épocas de conflictos como la de las grandes migraciones, el noble acude con esta organización armada a las campañas guerreras ${ }^{12}$.

El Gefolge de un Gefolgsherr (princeps, dux, urgerm. druhtin, ahd. truhtin) está formada por un número determinado de personas jóvenes libres. Son, en un principio, hijos de Gefolgsherr, para quienes la Gefolgschaft es el camino más adecuado para iniciarse en las armas. La relación entre las dos partes era similar a la de los miembros de la Sippe, con la peculiaridad de que el compromiso, regulado mediante contrato, podía romperse con más facilidad, de manera que la obligación de la lealtad sustituye a la de la obediencia. Así se crea una ética del honor que orienta todas las actuaciones de sus miembros. En cualquier caso, la relación entre ellos es todavía de naturaleza prefeudal, a pesar de que comience a hacerse frecuente la compensación por los servicios prestados, consistente, a veces, en la distribución de tierras.

Pues bien, ya se vio cómo los contenidos de las sagas, que de una u otra manera son conocidas, tienen que ver con acontecimientos de la época de las grandes migraciones; una época que cumple las peculiaridades específicas de una auténtica época heroica. No es por ello de extrañar que en ella el canto heroico adquiera un gran desarrollo.

Del informe de Tácito en el capítulo II de la Germania se deduce que ya en el siglo III antes de C. se ha cultivado poesía aliterante. Tácito habla de Die Abstammung der Germanen, especie de composición poética sobre el origen de los germanos. De la tradición poética que se establece y que perdura hasta el siglo IV, hablan las obras de Tácito (años 55115) Anales (año 109) Germania (año 98), la primera de ellas sobre la costumbre de cantar a Arminio y la segunda sobra la de cantar a Hércules al entrar en batalla y sobre la existencia de cantos (lat. carmina) denominados barditus; la Historia de los godos (de hacia el 550) de Jordanes (hacia 500-555/560) en que se informa sobre la composición "Gotische Wandersage"; los fragmentos de la Byzantinische Geschichte: Geschehnisse der Jahre 441472 de Prisco (hacia 415-472), diplomático en la corte de Atila; la Res gestae de Ammianus

12 Cfr. B. Gebhardt, Handbuch der deutschen Geschichte. Band 1: Frïhzeit und Mittelalter. In Verbindung mit mehreren Autoren. Edic. de H. Grundmann, Unio Verlag (Stuttgart 1954), pág. 594. 
Marcellinus (de hacia 330-395). De todos ellos se deduce el cultivo de al menos composiciones mnemotécnicas, himnos, coros, marchas, cantos de danza, cantos de boda, conjuros, nenias, elegías, composiciones melódicas religiosas y cantos heroicos ${ }^{13}$

Es en la época heroica por antonomasia en que se dan las circunstancias y condiciones adecuadas para el desarrollo del género más representativo de una época de esta naturaleza, como es el canto heroico.

Según los supuestos más defendibles puede pensarse que es entre los godos cuando en un momento de la historia se inicia un desarrollo de este género. Los godos inician a gran escala la gran migración y con ello una época. El repertorio supuesto de cantos heroicos a partir tanto de los informes de historiadores como de las obras conservadas, va desde los más antiguos del siglo V, como Ermanarichs Tod (de inicios del s. V, cuya forma definitiva es el Hamdierlied de los Edda), o Hunnenschlachtlied (de mediados del s. V; parte del cual se conserva en la Herwararsaga), pasando por los de los siglos V y VI, como el Urlied der Burgundenuntergang (que se corresponde con el Altes Atlilied de los Edda), Wielandlied (Wölundlied de los Edda), y tal vez la Ursaga des jüngeren Sigfrid ${ }^{14}$, hasta las manifestaciones finales de los siglos VI, VII y VIII, como Iringlied (canto turingio de principios del s. VIII), Alwin (del s. VI), Rosimundlied (de mediados del s. VII), Chlotarcharlied (de principios del s. VIII), Urlied von Rabenschlacht (de principios del s. VII), Hildebrandlied (del s. VIII), Sigfrids Tod (de entre los siglos VI y VII = Altes Sigurdlied de los Edda).

Son títulos suficientes para poder pensar que el canto heroico ha dominado el panorama literario durante mucho tiempo. Lo que no es de extrañar dadas las circunstancias. Los hombres de una época heroica sienten interés especial por conocer la historia y el destino de las figuras históricas representativas de su Stamm. En ellas ven reflejadas sus peculiaridades, sus creencias y sus anhelos. Se identifican con su tragedia porque personifican la tragedia de la propia tribu.

Por otra parte, puede admitirse que es una consecuencia lógica que el espíritu que dominaba en el grupo tuviese su manifestación en la activiad cultural y poética y que su forma de entender la vida y su propia historia encontrase justificación en sus cantos épicos. Los eskaldas, funcionarios de la creación poética fueron los encargados de ello ${ }^{15}$; su situación social ha de entenderse en tanto que son miembros de la estructura de la nobleza guerrera que desarrolla una forma de vida peculiar, que tiene reflejo en la creación de una jerarquía de distintos cargos y funciones ${ }^{16}$.

\footnotetext{
13 Para detalles sobre estos testimonio vid., F. Genzmer, "Vorgeschichtliche und frühgeschichtliche Zeit", H.O. Burger (Hrsg.), Annalen der deutschen Literatur. 1. Lieferung, Metzler (Stuttgart 1962), págs. 1-36.

${ }^{14}$ De esta época sería también el Urlied von Ingeld, del que hay vestigios en el Beowulf y en el Widsith.

15 Betz especula sobre la función también de sacerdote de estos poetas heroicos y aventura la pertenencia a un estamento específico. Cfr. W. Betz, op. cit., págs. 1878-1879, 1964-1965.
}

16 Cfr. W. Kellermann, op. cit. pág. 29. 
Prisco, el enviado bizantino, informa sobre músicos en la corte de Atila, a los que designa con el calificativo de bárbaros, que cantaban las "victorias y la virtudes guerreras del príncipe de los hunos". Según Halbach, el objeto de su actividad podrían ser composiciones poéticas del estilo de los himnos ${ }^{17}$.

Genzmer es de la opinión de que, en un principio, todos los estamentos participan en la creación literaria, sobre todo en lo que se refierea géneros simples, como historias cortas, sagas populares etc. Por lo que toca al canto heroico, su cultivo se reduce a autores que pertenecen al círculo de los poderosos y sus respectivos séquitos ${ }^{18}$; ello explicaría que en el periodo de máximo desarrollo de la literatura germánica y del canto heroico, el autor sea noble, actúe en la corte. Es denominado skop (a.a.m. scof, scopf; sinónimo de a.i. glēeman o léeodwyrrhta ( = a.a.a. liudari), y a.a.a. léedslekko ${ }^{19}$.

El poeta desarrolla una función oficial, bien porque corresponda con el interés social o político del grupo al que pertenece, bien porque ese grupo social y político se sirva de él una vez conseguido un desarrollo determinado. Lo más probable podría ser lo primero. Con el canto heroico se cumple la función de satisfacer los oídos de los oyentes mediante la recitación de hechos heroicos de miembros del Stamm, que les han llevado a un final no sólo desgraciado sino sobre todo trágico. Cuando estos hechos se propagan a otras Stämme menos implicados en los acontecimientos concretos y sobre todo en sus protagonistas, transforman sus contenidos en razón de los propios intereses. En este caso, el poeta cortesano, lleva a cabo un trabajo de adaptación a la función que él mismo ha de desarrollar y a la función que se le asigna a la obra y al propio género.

Es una tarea que en modo alguno entra en contradicción con la que estableciera Höfler y que coincide con la asignada a la literatura griega de cantar la fama de los hombres, y, siguiendo a Grimm, cantar la fama del héroe tal y como vive en el pueblo, es decir, algo que se siente como común aunque suprapersonal. Por ello la saga heroica se entiende como una "Verkörperung des Vergangenheitsbildes der Gemeinschaft", algo que ayuda a conformar la conciencia del pueblo y su identidad ${ }^{20}$.

Se trata de un punto de vista seguramente cierto, pero incompleto. La veneración de los héroes es, sin duda, en muchos casos, una necesidad que tiene que ver simplemente con la supervivencia, pero es una necesidad también de tipo político, determinada por una forma especial de organización, que es inherente a la naturaleza del séquito. El pueblo necesita un sentimiento de seguridad frente a la experiencia frecuente de la destrucción y la muerte. Necesita una explicación que proporcione un sentido a lo que está ocurriendo. El canto heroico cumple esta función.

\footnotetext{
${ }^{17}$ K. H. Halbach, "Epik des Mittelalters", Deutsche Philologie im Aufriß, pág. 403.

18 Cfr. op. cit., pág. 13.

${ }^{19}$ Sobre la etimología y significado del término skop, vid. E. Werlich, "Der westgermanische Skop", Zeitschrift für deutsche Philologie 86, (1967), págs. 352-374. Vid. también K. von See, "Skop und Skald. Zur Auffassung des Dichters bei den Germanen", Germanisch-Romanische Monatsschrift 14, (1964), págs. 1-14.

20 Cfr. O. Höfler, "Deutsche Heldensage", Zur germanisch-deutschen Heldensage. Hrsg. von K. Hauck, Wissenschaftliche Buchgesellschaft (Darmstadt) 1965, págs. 61-62.
} 
Para poder cumplir la función asignada al canto heroico, el poeta se sirve de los medios literarios que tiene a disposición y que sólo encuentra en la tradición. Un repertorio y un código que son muy reducidos; que han ido evolucionando muy lentamente hasta adoptar la forma como se manifiesta en las escasas fijaciones por escrito de que disponemos. A partir de un inicio, seguro que indogermánico, el código se estructura en razón de las peculiaridades de la lengua, más por el acento que por la medida o musicalidad. El resultado son formas simétricas, exactas y uniformes que se cultivan hasta, al menos, el siglo II d. C. (Ej. Havamal de los Edda; el himno Hyndloljód, también de los Edda; el 2. Merseburger Zauberspruch etc.); o, más tarde, formas, como es el caso del Hildebrandslied en que la versificación se caracteriza por la ausencia de estrofas, ocupando su lugar el verso largo como unidad métrica mayor, pasando por la conformación estrófica irregular de los cantos heoricos recogidos en la compilación Edda.

Este proceso permanente de "complicación" del código, lleva a un enriquecimiento progresivo del estilo, que podría establecerse como un camino con las siguientes estaciones: Abandono paulatino de elementos primitivos como el paralelismo; aparición de técnicas como la de la variación y el "Kenning" (ej. a.isl. vargtre = a.a.m. Wolfsbaum = Galge etc. del Hamdierlied: ); y mantenimiento del epíteto y aparición de la simbolización en un momento ya final (tal y como se aprecia igualmente en el Hamdierlied, y también en el Hunnenschlachtlied $)^{21}$.

Como elemento estructural de configuración literaria, el canto heroico utiliza una técnica descriptivo-narrativa épico-dramática; sus contenidos son fuerzas anímicas originarias y elementales como el amor, la amistad, la venganza etc. Los protagonistas de un contenido concentrado son héroes miembros de un séquito, cuyas cualidades fundamentales son la lealtad a la estirpe o, dado el caso, al séquito. La venganza se hace necesaria como muestra de estimación del honor y garantía de la supervivencia de sus miembros. Los héroes se encuentran enmarañados dentro de un destino trágico, que como manifestación de la Norne, puede interpretarse no como una fuerza completamente oscura e incontrolable, sino como la simbolización del sometimiento del personaje a la fuerza supraindividual que es la propia estirpe. Ello no quiere decir que el héroe del canto heroico sea consciente de las fuerzas a que está sometido. No entiende lo que ocurre a su alrededor aunque lo acepte de manera ciega. El canto heroico es, en este sentido, una configuración poética perfecta de una concepción existencial y un orden de vida en sus manifestaciones histórica, social fundamental, sin que con ello se excluya la política.

El Hildebrandslied es el último canto heroico trasmitido de la época final de la literatura germánica. Algunos autores, como Halbach, son de la opinión de que el género ha tenido que continuar su desarrollo durante los tres últimos siglos de la temprana edad media y que

${ }^{21}$ Cfr. el estudio de la evolución que hace Halbach comparando el Hildebrandslied con los cantos más antiguos de los Edda: Altes Sigurdlied, Altes Atlilied, Hamdierlied, Völundlied y Hunnenschlachtlied, en "Epik des Mittelalters", págs. 412-415. O Genzmer al comparar igualmente el Hildebrandslied con Völundlied, Hamdierlied y Altes Atlilied, en "Vorgeschichte und Frühgeschichtliche Zeit", págs. 32-34. 
su transmisión habría sido oral ${ }^{22}$. En cualquier caso, si exceptuamos la epopeya heroica de título Waltharius surgido entre los siglos IX y X, hasta el siglo XII no nos encontramos con literatura que de alguna manera evoque la heroica de épocas ya lejanas. La Kaiserchronik (1135-55), el König Rother (1150-70) y Herzog Ernst (de hacia 1180) son tres obras que de alguna manera tratan algunos de sus contenidos de manera heroica. A finales de siglo, sin embargo, ya se han consumado los presupuestos de la literatura medieval clásica, de la que el Nibelungenlied, obra heroica por excelencia, constituye una de las máximas aportaciones.

En una primera aproximación a la misma, se observan ya unas peculiaridades claramente diferenciadoras con respecto al canto heroico. En primer lugar, se trata de una obra escrita. En segundo lugar, de una obra mucho más extensa. En tercer lugar, de una forma de versificación, que en principio, no es germánica. En cuarto lugar, de un tipo de literatura representativa de la sociedad noble feudal. En quinto lugar, de factores de tensión poética propios del canto heroico, como el honor, la fidelidad, la venganza etc.; no obstante, aparecen otros nuevos, como la intriga, el engaño, lo grotesco etc. Por fin, es de observar un hecho llamativo: la presencia de mujeres como portadoras de la acción fundamental.

La reaparición de la literatura heroica ocurre en un momento de la historia, que es el resultado de un proceso, cuyos inicios se remiten a varios siglos atrás. En él se ha producido la síntesis de dos mundos y dos culturas; una síntesis que consiste en el surgimiento de una sociedad de signo completamente nuevo. Ambos aspectos son presupuestos necesarios para entender el cambio correspondiente que tiene lugar en la literatura heroica del siglo XIII.

El proceso de cristianización de los pueblos germánicos comienza relativamente pronto. Sin embargo, la síntesis no comienza a tomar estado de naturaleza hasta el siglo V momento de la formación del reino de los francos -, confirmándose en los siglos VIII y IX con la política de Carlomagno, fundamentada en la recuperación de la idea del dominio de toda Europa sobre el contenido dado a esta idea por Roma y la iglesia cristiana ${ }^{23}$. Aquí resulta legítimo referirse al reconocimiento generalizado de que con el tratado de Verdun (año 843) y el de Ribemont (año 880) los alemanes inician su autonomía histórica.

A partir de la creación del Imperio se consolida la estructura socio-política feudal (a. Lehnwesen). Dentro de este sistema la nobleza de espada (a. Dienstadel), en su categoría de nobleza feudal (a. Lehnsadel) y constituída en un principio fundamentalmente por condes, se entiende como representante de los intereses reales dentro del espacio de su jurisdicción con autonomía no sólo militar sino también administrativa. Con el paso del tiempo, parte del territorio administrado se convierte en propiedad (a. Eigenbesitz) o en propiedad feudal (a. Lehnbesitz), con lo que esta nobleza cobra la categoría de nobleza hereditaria (a. Erbadel). En época carolingia se establece una administración del estado fundamentada en ministerios

22 Cfr. Halbach, op. cit., pág. 420.

23 Cfr. Gebhardt, op. cit., pág. 609. 
feudales asignados a vasallos que han realizado juramento de fidelidad. Estas funciones podían igualmente convertirse en hereditarias.

En época de los Ottonen, Salier y Staufer tiene lugar una evolución muy llamativa, que puede entenderse como una programa de confirmación de la estructura política feudal. No obstante, el imperio feudal entra en crisis con los Salier como consecuencia de la conjunción de la Iglesia y el Estado, la lucha de las investiduras, el deseo de secularización de los príncipes y, en general de la nobleza y la caballería, el surgimiento de vasallos poderosos (a. Großvasallen) y sus exigencias que se materializan en la forma de principalidad (a. Fürstlichkeit) no sólo con autonomía, sino también con soberanía territorial.

Los emperadores Staufer intentan una renovación del imperio desde la idea romana de un imperio mundial, en el que se conserva el componente cristiano. De esta manera, se pretende una justificación de la sacralización del imperio, pero desde el sometimiento del papado a la orientación de la política imperial.

El resultado final consiste en el afianzamiento de una nobleza selecta (a. Hochadel), cuyo enfrentamiento con el emperador se saldará a su favor con el surgimiento de la clase de los príncipes imperiales (a. Reichsfürstenstand). La territorialización del imperio, por otra parte, supone además el sometimiento de la pequeña nobleza (a. Kleinadel). La idea de la renovación resulta un fracaso que se confirma en el siglo XIII en la lucha entre Welfen y Staufer. Las consecuencias para la pequeña nobleza - caballería y ministeriales - tiene gran importancia para la literatura heroica.

Tradicionalmente se han entendido la sociedad feudal como una sociedad constituída por tres estamentos. La estructura jerarquizada que conforma la pirámide feudal está fundamentada sobre una base muy amplia de población campesina. En un segundo nivel, muy estrechado ya, está la pequeña nobleza (a. niederer Adel) formada por caballeros y Ministerialen. Finalmente, los grandes nobles (a. Hochadel) - dentro de ella los príncipes y, al más alto nivel, el emperador. Los priores, abades, condes, condes palatinos y duques constituyen la categoría de los príncipes imperiales (a. Reichsfürsten), condicionada por derechos feudales especiales.

La caballería y ministerialidad forman el nivel más bajo de la nobleza. Las fronteras entre ambos grupos sociales no siempre resulta fácil de delimitar. Lo que sí se observa es que las múltiples luchas que tienen lugar dentro del sistema feudal están protagonizadas en el aspecto militar por la caballería. En cualquier caso, hacia 1200 la forma de vida de ambos apenas si se diferencia de la de la vieja nobleza, comparable incluso a la de los comerciantes de las ciudades ${ }^{24}$. En la época del Nibelungenlied los ministeriales son conscientes de su situación de privilegio. En cualquier caso, todos los niveles de la nobleza viven un momento de encapsulamiento frente a la gran masa de la población, como consecuencia de una forma de vida muy diferenciada, que pretenderán defender por todos los medios.

${ }^{24}$ Cfr. Bumke, Höfische Kultur. Literatur und Gesellschaft im hohem Mittealter, vol. 1, (München 1986), pág. 51. 
El núcleo fundamental de la vida es la corte. En ella se mueven el emperador y su familia, el clero cortesano de funciones religiosas y educativas, arquitectos, médicos y diplomáticos, cancilleres, notarios, escribanos etc.; en ella trabajan los ministeriales - con quienes conviven también los familiares más allegados - como funcionarios de la administración cortesa; invitados, mensajeros y diplomáticos y amplias masas de peticionarios y todo tipo de artistas, de entre los que uno de los más famosos es Walther von der Vogelweide ${ }^{25}$.

La corte, sea de las residencias, de los castillos, de la nobleza laica o nobleza clerical, se convierte en el centro neurálgico de una sociedad nueva que desarrolla formas de vida iguales y que comparte los mismos ideales. En ella el caballero guerrero se convierte en caballero cortesano.

Con los conceptos de corte y cortesano están en relación directa los de caballero y caballeresco, de gran importancia para toda la literatura del momento. El concepto de caballero encierra dos aspectos muy bien diferenciados. Encierra un sentido histórico-social y un sentido ético.

El caballero es el hombre a caballo, cuyas funciones son funciones fundamentalmente de servicio. Con las cruzadas la idea incluye también un contenido religioso; el caballero es servidor de Dios dentro de la organización que establece una ordo militaris. En el siglo XII el término se utiliza ambién para designar a los ministeriales, como nivel más bajo del estamento noble.

El concepto de caballero, por otro lado, puede aplicarse tanto al caballero como tal, como al príncipe o al señor. Es una connotación que comienza a abrirse paso en el siglo XII y que, separada de la fundamental anterior de militar, toma las de stattlich, schön, prächtig. En este sentido, el caballero, se identifica como una persona de carácter edele, guot, wert, gemeit $^{26}$. De todas esta cualidades va a estar dotado el caballero cortesano tal y como nos lo presenta no sólo la literatura de la época, sino también el caballero del Nibelungenlied.

Dentro de la producción literaria de hacia el año 1200 el Nibelungenlied se nos presenta como una obra que llama la atención por sus peculiaridades únicas. Difiere notablemente de las contemporáneas de decenio Parzival o Wigalois, Armer Heinrich o Lanzelet, de los Minnelieder de Wolfram von Eschenbach o de los Lieder gegen Reinmar den Alten de Walher von der Vogelweide.

Si se examina la producción de antes de ese año, puede observarse que no es muy diferente. Heinrich von Veldeke escribe Eneid, Hartmann von Aue Erec y Gregorius. Es la época de los Minnelieder de Friedrich von Hausen, Heinrich von Morungen, Reinmar der Alte, y de los de contenido de ebene Minne de Hartmann von Aue.

25 Cfr. Bumke, op. cit., págs. 76-77.

${ }^{26}$ Cfr. ibid., págs. 67-69. 
El panorama inmediato posterior a 1200 tampoco cambia mucho. Es la época de Tristan und Isolt de Gottfried von Straßburg, Willehalm y Titurel de Wolfram von Eschenbach, los Lieder der ebenen Minne der Walther von der Vogelweide, los Lieder de Neidhart von Reuental o los Kulturkritische Gedichte de Walther von der Vogelweide.

La aparición del Nibelungenlied coincide con el momento culminante del desarrollo de la literatura cortesana y, en consecuencia, con el momento de inflexión hacia nuevas posibilidades.

En el periodo inicial el caballero busca en esta literatura una respuesta a al mundo que ha idealizado; una respuesta que puede calificarse de funcional. Como hombre de corte, encuentra una confirmación literaria en fuentes francesas; así surgen obras como Alexanderlied (de hacia 1140-1150) del Pfaffe Lamprecht, Straßburger Alexander (de hacia 1170), Rolandslied del Pfaffe Konrad (también de hacia 1170), Graf Rudolf (fragmento de entre 1170-1180), Tristant de Eilhart von Oberg (de hacia 1170) o Reinhart Fuchs (obra fragmentaria de entre 1170-1180). Por contra, como guerrero que es, el caballero busca modelos de comportamiento en el pasado, busca identificar sus ideales en la propia tradición; obras características de esta orientación son König Rother y Herzog Ernst (de los decenios respectivamente 1160 y 1170) a las que por otras razones se ha hecho ya mención aquí. Ello no excluye el gusto por materiales fantásticos propios de la literatura juglaresca, tal y como ocurre en obras como Oswald, Orendel y Salman und Morolf.

En este momento de transición entre siglos tienen lugar grandes transformaciones. Especialmente como consecuencia del abandono de la exclusividad de los contenidos religiosos y cronicales, la lengua literaria ha dejado de ser el latín para ceder protagonismo a la lengua popular. Además, los centros de producción se extienden a las cancillerías, las cortes y más tarde a las ciudades como respuesta a intereses sociales y ambiciones de poder. La nobleza, que en gran medida continúa siendo analfabeta, comienza a sentir intereses culturales e invade el terreno a hasta entonces reservado a los clérigos, asumimiendo en ocasiones mecenazgos y promoviendo proyectos literarios ${ }^{27}$. Ello que no excluye que los clérigos continúen siendo los autores. Por otro lado, la literatura se produce y transmite de dos formas: como literatura escrita de funciones claramente religiosas y como literatura oral, cuya función es lúdica y de entretenimiento y diversión.

Esta situación de analfabetismo, los intereses sociales y de poder y las necesidades de autoafirmación con el cultivo de la épica heroica tradicional, hacen que la literatura se convierta en literatura escrita que necesita de un mediador al que se le asignan nuevas funciones.

Si bien se dispone de más información del poeta cortesano que del poeta germánico, tampoco se sabe mucho de él. Sí puede afirmarse que ahora es el momento en que empieza a perder el anonimato, lo que, por otra parte, no excluye la continuidad de autor anónimo. Los poetas que han perdido el anonimato son poetas fundamentalmente líricos, tanto 
Minnesänger como Spruchdichter, y autores épicos. La razón de la pérdida del anonimato ha de ser buscada también en el cambio que se ha producido en la función de la literatura a partir del punto en que ha conseguido un carácter social. La lectura literaria social, en grupo, que, como tal, puede constituir parte de una velada, se convierte en el medio de expresión de los ideales cortesanos, en la que apenas tienen cabida los problemas de la vida de todos los días. Se trata, por tanto, del poeta consciente de que hace de mediador de esos contenidos para los que ha sido encargado y pagado y, en consecuencia, busca darse a conocer.

Por otro lado, están también los autores desconocidos que se enmarcan dentro de la tradición literaria más popular, pero que llegado un momento emprenden trabajos que sobrepasan esa tradición. Ello quiere decir que, sin abandonar los temas o las formas de expresión de la literatura heroica, se acercan a formas de expresión más actuales. Se apropian de la escritura como forma de reproducción literaria y abandonan, en gran medida, la función de mediador-compositor que habían desempeñado antes. Reconocen una mayor aceptación de la literatura cortesana que la heroica y siguen, por ello, sin manifestar su nombre. No es algo un trabajo propio de la nobleza, sea laica o religiosa, como dicen Schneider / Mohr y por ello prefieren el anonimato. Es el caso del autor noble del Nibelungenlied.

Hasta aproximadamente treinta años más tarde, no se continúa el camino literario abierto por el Nibelungenlied. Ello hace patente la unicidad y rareza de la obra. Hay en ella, sin embagro, muchos aspectos que encunetran fácil explicación desde los presupuestos de la literatura cortesano-caballeresca.

El Nibelungenlied está configurado desde una ambientación cortesana genuina. Se describen, ya desde la primera aventiure, las cortes de las ciudades de Worms y Xanten y especialmente la vida cortesana de las fiestas, los torneos que tienen lugar en ellas y la riqueza y el lujo que envuelve todo. Es la vida de una sociedad que rinde culto al amor cortesano. Günther busca a Brühnhild, Siegfried a Kriemhild. Ninguno de los dos ha visto a esas mujeres, sólo han oído hablar de sus atributos cortesanos. Por otro lado, Siegfried está dotado de las virtudes físicas y morales que le hacen modelo de caballero cortesano; es bien educado y observa todas las formas que corresponden al estamento al que pertenece; es un auténtico vasallo (mhd. lehnman) en la corte del rey de los burgundios tal y como corresponde a una organización feudal. De las mismas virtudes están dotados la práctica totalidad de los personajes.

Independientemente de, como veremos más tarde, todo esto encaja plenamente dentro de los principios de la ética caballersca, se observan elementos disonantes que no se explican del todo desde los principios de la literatura cortesano-caballeresca. Es algo que se observa, en principio, en elementos formales tales como la versificación, que frente al pareado de la literatura cortesana, el Nibelungenlied utiliza el verso largo en configuración estrófica. El vocabulario no es arcaizante, lo que no ocurre en a épica cortesano-caballeresca. El estilo narrativo es unidimensional, sólo desarrolla una acción externa y no doble, es decir, no desarrolla, como aquélla una acción externa y otra externa, utiliza la técnica del retardamiento y la anticipación, muestra una tendencia clara a la hipérbole y se sirve de la 
variación y de la aliteración. Los materiales no son ni de procedencia antigua, francesa o celta, sino de procedencia germánica.

El Nibelungenlied es una obra anónima. No son pocas las hipótesis que se han barajado sobre la procedencia del autor. Sea como fuere, no parece descabellado pensar que se trata de una continuación de la literatura oral que responde de manera adecuada a lo que es el conjunto de la literatura heroica germánica y sus formas de transmisión y propagación. Desde esta perspectiva el poeta habría de ser entendido como el poeta germánico tanto de la época de las grandes migraciones como de épocas posteriores, esto es, no como autores sino como portadores y transmisores de una tradición. En este sentido, es como habría que entender tanto el primer verso del Hildebrandslied como el primero del Nibelungenlied. El carácter de anonimidad del Nibelungenlied se explicaría desde las razones ya expuestas, es decir, entre otras, desde la consciencia de menor calidad de la literatura popular.

Pero tampoco desde esta premisa se termina de explicar lo que no se explicó desde premisas cortesano-caballerescas. Es el caso de la aventura, de claras connotaciones fantásticas, de Siegfried con el dragón, o la propia figura de Siegfried de procedencia histórica imposible de determinar. Es también la aparición del engaño y de la astucia, que no encaja ni en la literatura cortesano-caballeresca ni en la heroica. El concepto de lealtad de tiempos pasados parece resquebrajarse: Siegfried sirve a su señor, pero detrás está el interés por su hermana. La misma muerte de Siegfried a manos Hagen, en quien, en principio, parece pervivir la lealtad propia de la época germánica, será fruto del engaño. La explicación a todo ello sólo puede encontrarse en la tradición de la literatura precortesana de los Vaganten, que con el tiempo encontrará continuidad en la juglaresca (a. Spielmannsdichtung), en que es frecuente el ingenio y la fantasía, exageraciones y desarrollos propios de géneros fantásticos como el cuento. Lo que, por otra parte, sería una prueba que confirma la evolución que esta teniendo lugar en la configuración de los elementos funcionales de la producción y recepción de la literatura del siglo XII.

De las consideraciones realizadas, se pueden sacar las siguientes conclusiones.

El canto heroico (a. Heldenlied) es la forma literaria oral que surge como consecuencia de acontecimientos heroicos, que se consagra durante la época de las grandes migraciones germánicas (a. Völkerwanderungszeit). Es una época que supone la integración, aunque sólo sea parcial, en el mundo y la cultura cristiano-latinos, que traerá como resultado una síntesis histórica y cultural.

El canto heroico se entiende a partir de la configuración social y guerrera del componente germánico. De la misma manera que la organización social, bien sea en forma de Sippe, de Stamm, de Stammverband o de Stammverbände, la organización guerrera o Gefolge estructurada sobre una idea de vasallaje prefeudal (a. Gefolgschaftswesen) - se fundamenta sobre los principios de libertad, honor y lealtad.

Desde estos presupuestos el canto heroico toma una configuración literaria que se ha ido estableciendo a lo largo de varios siglos y que, en un momento dado, se construye sobre 
formas narrativas que dominarán el panorama de la literatura germánica hasta su desaparición.

El canto heroico es literatura oral que se produce en los centros de poder. A sus autores se les puede suponer el status de funcionario. Son miembros de la Sippe y del Gefolge. El lugar de recepción es, en tiempo de paz, la corte y seguro que los campamentos y castillos en tiempo de guerra.

El proceso de creación es una respuesta a un función estético-poética consistente en entretener a los oyentes informándoles sobre hechos del pasado protagonizados por el Stamm al que pertenecen o, en cualquier caso, por cualquier otro pueblo germánico, a fin de alabarlos como hechos heroicos y, no en último término, venerar a sus protagonistas. La función del canto heroico se entiende además como una respuesta a la necesidad de supervivencia en situaciones muy difíciles, sin excluir la posibilidad de una utilización política.

El código literario resultante se caracteriza por la versificación indogermánica con las peculiaridades propias del uso germánico de la misma, que son un resultado proveniente de la naturaleza peculiar y diferenciada de las lenguas germánicas. Por otra parte y con el paso del tiempo, el canto heroico experimenta un desarrollo estilístico que va desde el abandono de elementos primitivos - paralelismo etc. - a la utilización de recursos más complicados variación, kenning, epíteto, formas de simbolización etc. - Es el código literario de una nobleza guerrera organizada de manera prefeudal y estricta. Representa una sociedad, cuyos principios son la libertad, la lealtad, el honor de la estirpe; una sociedad que entiende el destino - la Norne originaria - en solución trágica. Es un código literario germánico, a pesar de que en alguna muy rara ocasión pueda identificarse algún elemento cristiano. La síntesis de culturas aún no se refleja en él.

La epopeya heroica, en cambio, se explica como configuración de la síntesis de esas dos culturas. Esta síntesis se manifiesta en la confirmación del feudalismo como forma de organización política y social, en la que se establece la nobleza como estamento social dominante en sus diferentes niveles, que, como tal, se mantendrá a lo largo de siglos.

Dentro del estamento noble se desarrolla la clase caballeresca, que en el siglo XII consigue un status privilegiado que querrá mantener, hasta el punto de justificarlo desde principios éticos y morales. Al igual que el resto de la nobleza pasará por un proceso de encapsulamiento social dentro de la corte y desarrollará un modo de vida sobre la base de vores éticos y morales totalmente idealizantes.

La epopeya heroica se consagra hacia el año 1200 dentro de un contexto literario dominado por la literatura cortesano-caballeresca y, aunque en menor grado, también por la literatura juglaresca (a. Spelmannsdichtung). Esto courre en un momento en que la producción y recepción literarias tienen lugar sobre todo en las cortes de la nobleza laica o religiosa. Que ello implique que el productor sea una persona culta, no excluye en modo alguno la existencia del autor popular. 
La epopeya heroica configura un código literario a partir de la tradición de la literatura heroica que hasta ese momento había pasado por una existencia cuando menos oscura.

La epopeya heroica es literatura heroica representativa de la sociedad feudal y de todas las contradicciones que esta sociedad comporta. Cumple la función propia de la literatura cortesana desde la consideración del caballero en sus dos facetas - guerrero y cortesano -. Para ello encuentra los modelos adecuados con más facilidad en la tradición heroica germánica que en otras tradiciones. No obstante estos modelos, la solución será al final cristiana.

La epopeya heroica utiliza materiales de las sagas de la época de las grandes migraciones, configurándolos desde tres presupuestos fundamentales: La literatura cortesano-caballeresca; la tradición oral propia de la literatura heroica; y la literatura fantástica tal y como se ha configurado en la literatura juglaresca (a. Spielmannsdichtung).

La ambientación es la propia de la literatura cortesano-caballeresca y sus personajes están dotados de las virtudes propias de los personajes de esa literatura. La acción se desarrolla como la actividad heroica más genuina y algunas de las virtudes de los protagonistas son las propias de los personajes del canto heroico. Sin embargo, tanto aquellos atributos propios de la ética caballeresca como éstos de la tradición germánica, se configuran como atributos contaminados por otros propios de un momento histórico más actual, como la intriga, el engaño, la astucia etc. en conformación a veces incluso incluso grotesca.

La forma de versificación es estrófica y la lengua arcaizante. En el Nibelungenlied se hace uso de técnicas también arcaizantes, se configura un estilo unilateral y se desarrollan recursos como el retardamiento y la anticipación, la variación, la aliteración etc. 
